\title{
Lack of interleukin-1 type 1 receptor enhances the accumulation of mutant huntingtin in the striatum and exacerbates the neurological phenotypes of Huntington's disease mice
}

\author{
Chuan-En Wang, Shihua Li, Xiao-Jiang Li
}

\begin{abstract}
Huntington's disease results from expansion of a glutamine repeat ( $>36$ glutamines) in the N-terminal region of huntingtin (htt) and is characterized by preferential neurodegeneration in the striatum of the brain. N171-82Q mice that express N-terminal 171 amino acids of htt with an 82-glutamine repeat show severe neurological phenotypes and die early, suggesting that N-terminal mutant htt is pathogenic. In addition, various cellular factors and genetic modifiers are found to modulate the cytotoxicity of mutant htt. Understanding the contribution of these factors to HD pathogenesis will help identify therapeutics for this disease. To investigate the role of interleukin type 1 (IL-1), a cytokine that has been implicated in various neurological diseases, in HD neurological symptoms, we crossed N171-82Q mice to type I IL-1 receptor (IL-1RI) knockout mice. Mice lacking IL-1RI and expressing N171-82Q show more severe neurological symptoms than N171-82Q or IL-1RI knockout mice, suggesting that lack of IL-1RI can promote the neuronal toxicity of mutant htt. Lack of IL-1RI also increases the accumulation of transgenic mutant htt in the striatum in N171-82Q mice. Since IL-1RI signaling mediates both toxic and protective effects on neurons, its basal function and protective effects may be important for preventing the neuropathology seen in HD.
\end{abstract}

\section{Background}

Huntington's disease is characterized by late-onset neurodegeneration that occurs preferentially in the striatum $[1,2]$. This selective neurodegeneration is caused by expansion of a polyglutamine (polyQ) tract in the $\mathrm{N}$-terminal region of huntingtin (htt), a large protein that consists of 3144 amino acids and is expressed ubiquitously in all types of cells throughout the body and brain. N-terminal fragments of mutant htt can affect intracellular trafficking [3-6] and enter the nucleus to alter gene expression $[7,8]$. Although we know that an expanded polyQ causes the misfolding of $\mathrm{N}$-terminal htt and induces cytotoxicity, the mechanism underlying the selective neurodegeneration remains unclear.

Transgenic mouse models expressing mutant htt make a highly valuable model for untangling the pathogenesis of HD. Of a number of HD mouse models that have been established, N171-82 HD mice have been investigated

\footnotetext{
* Correspondence: xli2@emory.edu

Department of Human Genetics, Emory University, Atlanta, GA 30322, USA
}

extensively because of their robust neurological phenotypes. N171-82Q mice express N-terminal 171 amino acids of human htt with an $82 \mathrm{Q}$ repeat under the control of the prion promoter, which drives gene expression at a high level in neuronal cells [9]. As a result, mutant htt is abundantly expressed in neuronal cells in the cortex and striatum of N171-82Q mice, causing motor function deficits, body weight loss, and early death that often occurs at 5-6 months in these mice [9]. The robust and progressive neurological phenotypes of N171-82Q mice offer an advantage for identifying therapeutics that can alleviate neurological symptoms and for uncovering pathogenic mechanisms $[10,11]$. Nonetheless, although the involvement of neuroinflammation and cytokines are known to be involved in a number of neurological disorders, their roles in HD remain elusive.

Interleukin-1 (IL-1), a 17-kDa polypeptide, is the prototypical cytokine with pleiotropic effects and is dramatically upregulated during neuroinflammation [12]. Considerable efforts have been made to alter IL-1 signaling for the 
purpose of reducing the inflammation in acute pathological conditions. However, the effects of IL-1 appear to differ depending on its expression levels and the target organ. IL-1 functions as a mediator or inhibitor of diverse forms of neurodegeneration [12,13]. For example, IL-1 activates NF-kB signaling $[12,14]$, which can be either protective of or destructive to cells $[14,16]$. Mutant htt can reduce NF$\mathrm{kB}$ [17] and also increase NF-kB signaling [18] in cultured cells. Given both the pathogenic and protective functions of IL- 1 and NF-kB, it is important that we understand the contribution of IL-1 signaling to the pathogenesis of HD.

Two well-characterized isoforms of IL-1, IL-1alpha and IL-1beta [19], can bind type I IL-1 receptor (IL-1RI) to trigger IL-1 signaling pathways. An endogenous antagonist (IL-1Ra) binds to IL-1RI and blocks IL-1 binding and signaling [20], conferring protection against pathologic events caused by the elevated level of IL-1. In this study, we crossed N171-82Q HD mice to IL-1RI knockout mice, in which NF- $\kappa \mathrm{B}$ activation is inactive at all times $[12,14]$. We found that diminishing IL-1RI could increase the accumulation of mutant htt in the striatum and exacerbate the neurological symptoms of N171-82Q mice. Our findings suggest that the basal activity of IL-1RI is important for preventing the accumulation of mutant htt in striatal neurons and hence related neuropathogenic events, which could be helpful for the development of new strategies to treat HD.

\section{Methods}

\section{Animals}

All animal procedures were approved by the Institutional Animal Care and Use Committee of Emory University. N171-82Q mice (B6C3F1/J-Tg(HD82Gln)81Dbo/J, Jackson Laboratory, Bar Harbour, ME, USA) and IL-1RI knockout

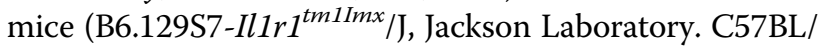
6) were obtained from the Jackson Laboratory and were maintained in the animal facility at Emory University in accordance with institutional guidelines. Male N171-82Q mice were mated with female IL-1RI knockout mice to generate HD-IL1R+/- mice. HD-IL1R-/- mice were then generated by mating HD-IL1RI+/- mice with IL-1RI null mice. PCR genotyping of transgenic mutant htt used the following primers (forward: 5'-CTA CGA GTC CCT CAA GTC CTT CCA GC-3' and reverse: 5'-GAC GCA GCA GCG GCT GTG CCT G-3'). IL-1RI gene deletion was verified by PCR with the following primers (forward: 5'-CCA CAT ATT CTC CAT CAT CTC TGC TGG TA-3' and reverse: 5'-TTT CGA ATC TCA GTT GTC AAG TGT GTC CC-3') for the wild type IL-1RI allele and the primers (forward: 5'-CTG AAT GAA CTG CAG GAC GA-3' and reverse: 5'-ATA CTT TCT CGG CAG GAG CA-3') for the mutated IL-1RI allele. The following PCR condition was used for the wild type and mutant IL1R gene: $94^{\circ} \mathrm{C}$ for $3 \mathrm{~min}$, followed by 33 cycles of $45 \mathrm{~s}$ at $94^{\circ} \mathrm{C}, 45 \mathrm{~s}$ at the annealing temperature $63^{\circ} \mathrm{C}$, and $60 \mathrm{~s}$ at $72^{\circ} \mathrm{C}$. For the specific amplification of human htt, the annealing temperature was $64^{\circ} \mathrm{C}$. The last cycle was followed by a final elongation step at $72^{\circ} \mathrm{C}$ for $10 \mathrm{~min}$.

\section{Antibodies}

The anti-huntingtin antibody (rabbit EM48) was previously produced in our laboratory [21]. The mouse anti-gamma-tubulin antibody was purchased from SigmaAldrich (St. Louis, MO) and used at 1:50,000 dilution. The mouse antibody to GFAP was obtained from Millipore Inc. Secondary antibodies were peroxidase-conjugated donkey anti-mouse or donkey anti-rabbit IgG $(\mathrm{H}+\mathrm{L})$ from Jackson ImmunoResearch (West Grove, PA).

\section{Rotarod test}

Movement coordination performance was evaluated using an AccuRotor rotarod apparatus (AccuScan Instruments). Mice were trained on 2 consecutive days for 35 -min trials at $5 \mathrm{rpm}$. Testing was performed on the third day. During testing, the rotating rod was set to accelerate from 0 to $40 \mathrm{rpm}$ in $5 \mathrm{~min}$. Each mouse performed 3 trials on testing day, with 5 -min resting periods between each trial. Latency to fall from the rotating rod was measured and averaged for the 3 trials.

\section{Immunocytochemistry and western blot analysis}

Mouse brain regions were carefully dissected from one hemisphere for western blot analysis, and another hemisphere was frozen in O.C.T. on dry ice for cryosectioning. Sagittal sections were cut at $15 \mu \mathrm{m}$ thickness using a cryostat (Leica CM1850), fixed in 4\% paraformaldehyde for $20 \mathrm{~min}$ and stained with antibodies as described previously [22]. Mouse EM48 (1:100) and rabbit GFAP $(1: 1,000)$ antibodies were used for double immunohistochemical analysis. For DAB (3,3'-Diaminobenzidine) staining, mice were anesthetized and perfused intracardially with phosphate-buffered saline (PBS, $\mathrm{pH}$ 7.2) for $30 \mathrm{~s}$ followed by $4 \%$ paraformaldehyde in $0.1 \mathrm{M}$ phosphate buffer (PB) at pH 7.2. Brains were removed, cryoprotected in $30 \%$ sucrose at $4^{\circ} \mathrm{C}$, and sectioned at $40 \mu \mathrm{m}$ using a cryostat. Free-floating sections were preblocked in $3 \% \mathrm{BSA}$ with $2 \%$ normal donkey serum and incubated with rabbit EM48 $(1: 1,000)$ as previously described [21]. Western blotting analysis of mouse brain tissues was performed as described previously [21]. Blots were probed with mouse EM48 (1:100), mouse anti-GFAP (1:2,000), and mouse anti-gamma-tubulin (1:50,000).

\section{Statistical analysis}

Results generated from 3 or more independent experiments are expressed as the mean $\pm S D$ and were analyzed for statistical significance using a 2-tailed Student's t-test. 


\section{Results}

There are two homologous receptors for IL-1 (type I IL-1R and type II IL-1R) that can bind either IL-1alpha or IL-1beta. However, type I IL-1R binds IL-1alpha with 10-fold greater affinity than it does IL-1beta. Moreover, type I IL-1, but not type II, receptor is important for IL-1 signaling [12]. Type 1 IL-1R (referred to as IL-1RI) null mice live normally and display no overt phenotypes or behavioral abnormalities [14], allowing us to examine whether a lack of IL-1RI could alter the neurological symptoms of HD mice. To this end, we crossed N17182Q mice (B6C3F1/J-Tg(HD82Gln)81Dbo/J, Jackson Laboratory, Bar Harbour, ME, USA) to IL-1RI knockout

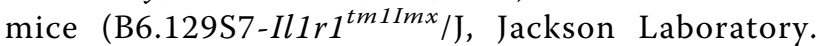
C57BL/6) and generated mice of different genotypes (Figure 1A).

We did not find any significant differences in survival and body weight between N171-82Q mice with and without the IL-1RI gene (data not shown). Rotarod performance has been widely used to assess the motor function of N171-82Q mice [9,21]; we found that N171$82 \mathrm{Q}$ mice fell much faster from the rotating rod than IL-1RI knockout mice, indicating a significant motor deficit in HD mice (Figure 1B). There was no significant difference in rotarod performance between female and male IL-1RI knockout mice. Because genetic background might influence mouse behaviors, we focused on the comparison between heterozygous IL-1RI and homozygous IL-1RI knockout mice on the N171-82Q background. These mice carry the same mutations (the mutant htt and targeted IL-1RI genes), so the difference between these two mouse lines is more likely to reflect any effects of IL-1RI expression on HD-related neurological phenotypes. N171-82Q mice lacking IL-1RI (HD-IL1R-/-) performed worse on the rotarod than N171-82Q mice with one copy of the IL-1RI gene (HD-IL1R+/-), regardless of sex (Figure 1B). Combining male and female mice, this difference is statistically significant (Figure 1C), indicating that lack of IL-1RI can exacerbate the motor dysfunction of HD mice.

We then examined the expression level of mutant htt in different regions of the mouse brain, including the striatum, cortex, hippocampus, and lateral globus pallidus (LGP), a region that is innervated by striatal neurons. Immunohistochemical studies with EM48, an antibody that preferentially reacts with mutant htt [21], revealed that more mutant htt aggregates were present in HDIL1R-/- mice than HD-IL1R+/- mice (Figure 2A). Highmagnification micrographs show that mutant htt formed inclusions as well as small neuropil aggregates in the nucleus (Figure 2B). Increased glial fibrillary acidic protein (GFAP) staining, which reflects early neurodegeneration, has been found in a variety of HD mice $[23,24]$.
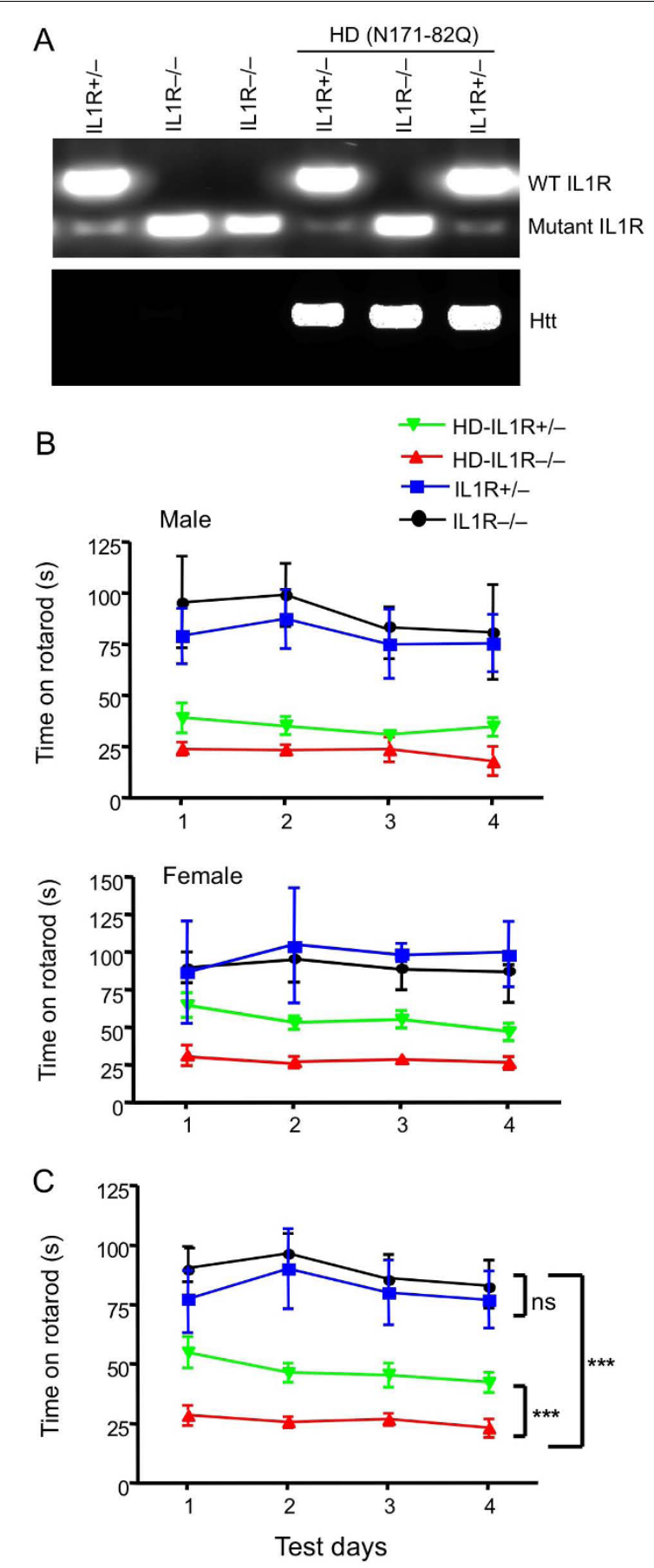

Figure 1 Lack of IL-1RI leads to rotarod deficits in N171-82Q mice. (A) Genomic DNA PCR analysis of mice of different genotypes. N171-82Q mice with (HD-IL-1R+/-) or without (HDIL 1R-/-) one copy of the IL-1RI gene were used for further comparison. Wild type (350 bp) and mutant (172 bp) IL1R products are indicated. (B) Male and female rotarod performances of (HD$\| \mathrm{L} 1 \mathrm{R}+/-),(\mathrm{HD}-\mid \mathrm{L} 1 \mathrm{R}-/-), 1 \mathrm{R}+/$ - , and $1 \mathrm{R}-/-$ mice at the age of 3 months were examined and compared. $n=10$ each group. (C) The rotarod performance of both male and female mice of different genotypes as indicated in (B). $n=10$ each group. ${ }^{*} p<0.01$. 


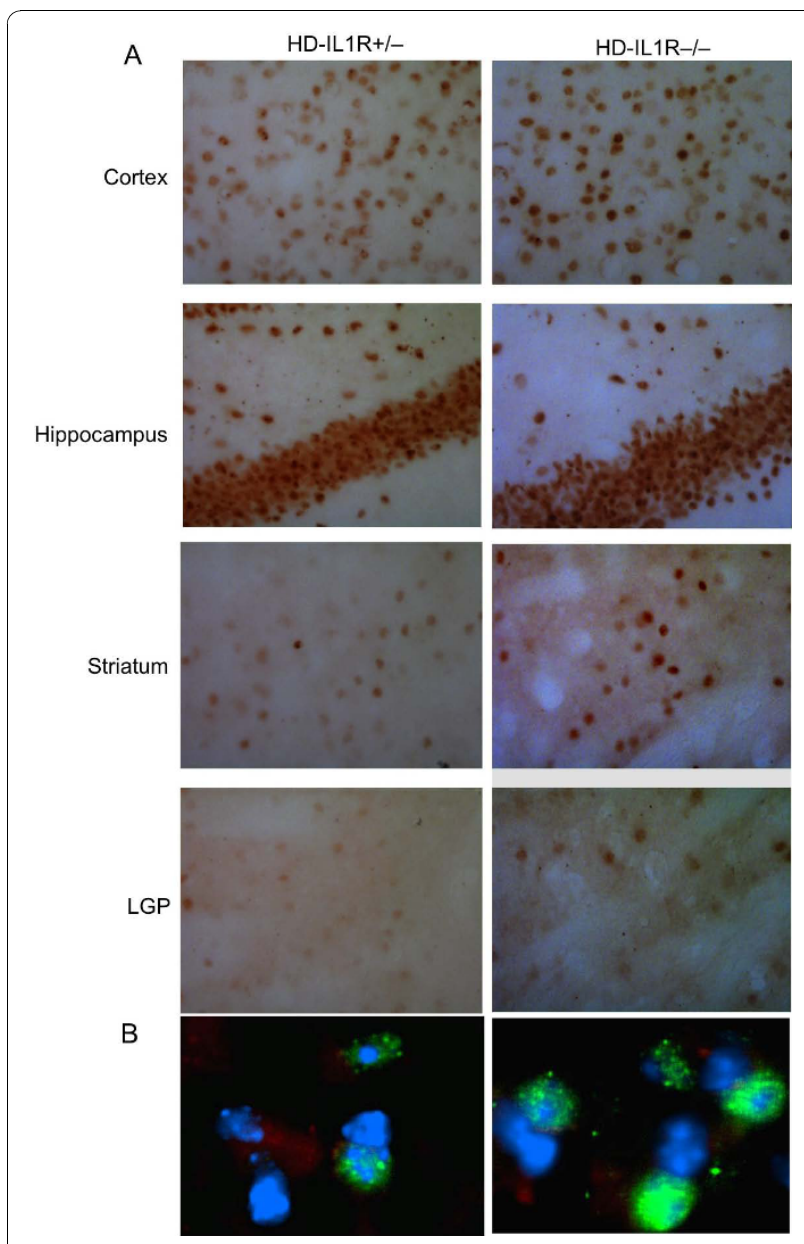

Figure 2 Increased accumulation of mutant htt in the HD mouse brain when IL-1RI is absent. (A) EM48 immunostaining (20X) showing the increased staining of mutant htt in the brain regions [cortex, striatum, lateral globus pallidus (LGP), hippocampus] of HD-IL1R-/- mice compared with HD-IL1R+/- mice. This increase is more prominent in the striatum of HD-IL1R-/- mice. (B) Fluorescent staining showing that mutant htt (green) is more abundant in the nuclei (blue), with small aggregates that are outside the nucleus and that were characterized previously as neuropil htt aggregates.

Compared with HD-IL1R+/- mice, there were more GFAP-positive cells in HD-IL1R-/- mice in the cortex and striatum (Figure 3A). Increased GFAP staining (red) is clearly shown in high-magnification micrographs that reveal mutant htt (green) in the nuclei (blue) of neuronal cells (Figure 3B). To verify this difference, we performed western blotting analysis of the brain tissues from mice of different genotypes. Htt immunoreactive products that were only present in samples from HD mice represent protein products of transgenic mutant htt (Figure 4). We found that aggregated htt, which is evident in the stacking gel, is more intense in the brain tissue sample from
HD-IL1R-/- mice than HD-IL1R+/- mice. This difference is especially pronounced in the striatal tissues. There was also a consistent increase in soluble mutant htt (arrows in Figure 4) in the striatal tissue from HD-IL1R-/- mice. More importantly, the GFAP level was also elevated in the striatal tissue of HD-IL1R-/- mice (Figure 4).

\section{Discussion}

Our findings show that depletion of IL-1RI can exacerbate motor deficits and increase the expression level of mutant htt in the brain, the striatum in particular. Thus, the basal level of IL-1 signaling is likely important for clearing mutant htt in neuronal cells. In N171-82Q mice, N-terminal mutant htt fragments are expressed in neuronal cells, leading to progressive htt aggregation and robust neurological symptoms [9]. The fact that $\mathrm{N}$-terminal mutant htt is prone to protein misfolding and is toxic to neuronal cells is in keeping with the idea that the proteolysis of disease proteins is critical for the pathology of HD and other neurological disorders [8,25-29]. Because these disease proteins progressively accumulate in neurons in HD and other diseases, clearance of these proteins is obviously key for preventing their neurotoxicity. The basal level of IL-1RI signaling may facilitate the clearance of mutant htt.

Although the deleterious role of IL-1 in acute brain injury has been firmly established in the vast majority of experimental models under inflammatory conditions, IL-1 can also regulate neuronal function under normal conditions [30-32]. This regulatory function is found to range from neurotrophic factors-like activity [33] to modulatory action on ion channels [31]. Our studies suggest that the lack of such neuromodulatory functions from IL-1RI can promote the neuronal toxicity of mutant htt. A second possibility is that IL-1 provides neuroprotection under specific experimental conditions (preconditioning), as IL-1 alone given prior to major lesions results in better outcomes, and the administration of IL-1RIa after preconditioning lesions reduces the resistance to injury [34]. The increased accumulation of mutant htt in striatal tissues in the absence of IL-1RI suggests that the basal activity of IL-1RI could regulate the normal function of the ubiquitin proteasome system and autophagy, both of which are important for removing misfolded proteins. Furthermore, the increased GFAP staining in N171-82Q mice [23] suggests that neuronal expression of mutant htt can increase the number of reactive astrocytes. Because IL-1RI in neurons mediates neuronal excitability, whereas IL-1RI in astrocytes may mediate the neuronal protective effects under hostile conditions [35], another possibility is that a lack of IL-1RI in glial cells may attenuate the protective 


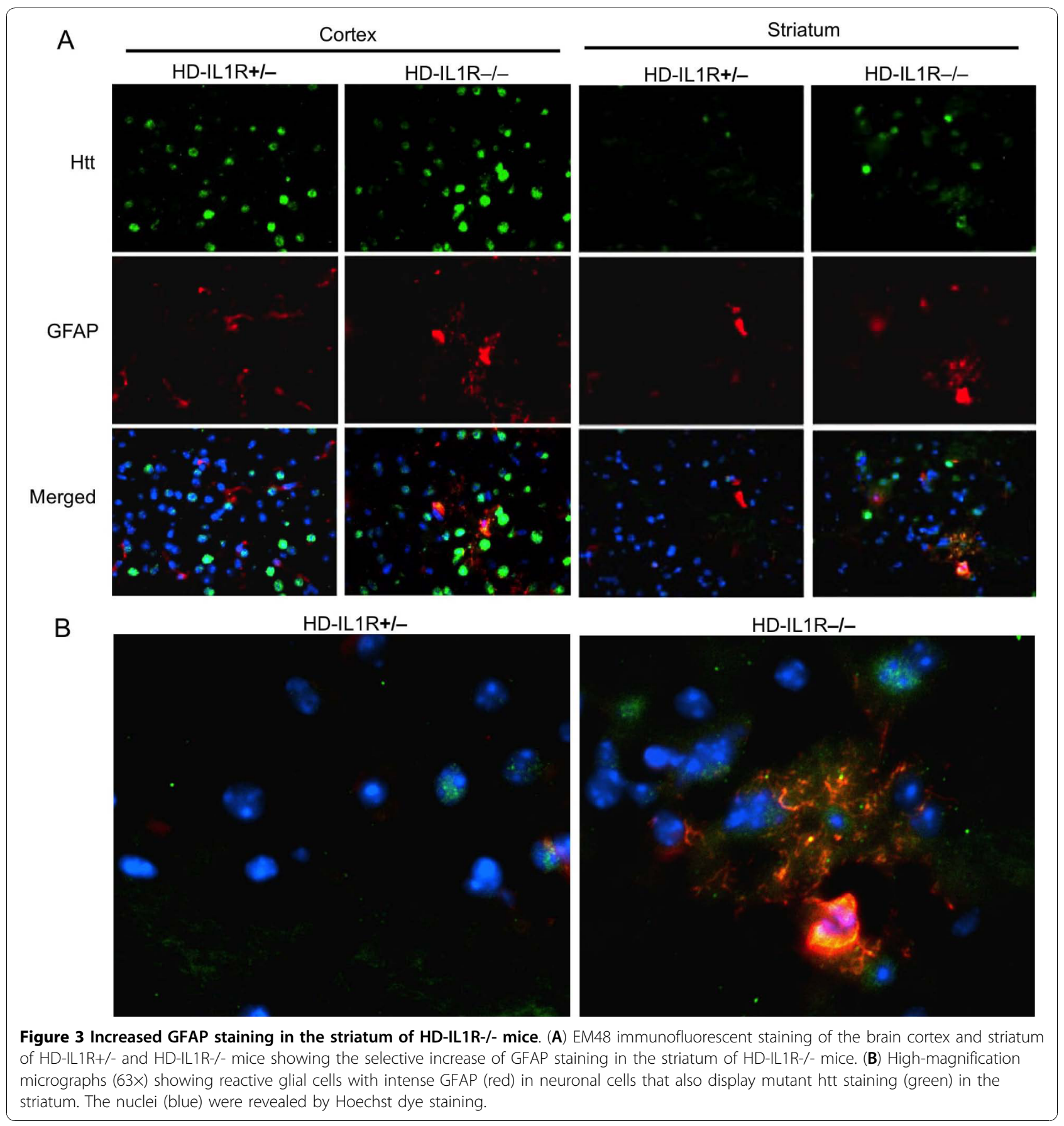

effects of IL-1 on the neuronal toxicity of mutant htt. In most HD mouse models, overt neurodegeneration and apoptosis are not observed. Thus, neuronal dysfunction rather than neuronal loss is more important for neurological symptoms seen in HD mice. Normal glial function is critical for preventing neurodegeneration, and the expression of mutant htt and other misfolded proteins in glial cells can lead to neurological symptoms in transgenic mice $[36,37]$. Thus, the findings of our study suggest that altering IL-1 signaling as a means of therapy for HD must take into account both its protective and destructive effects. 


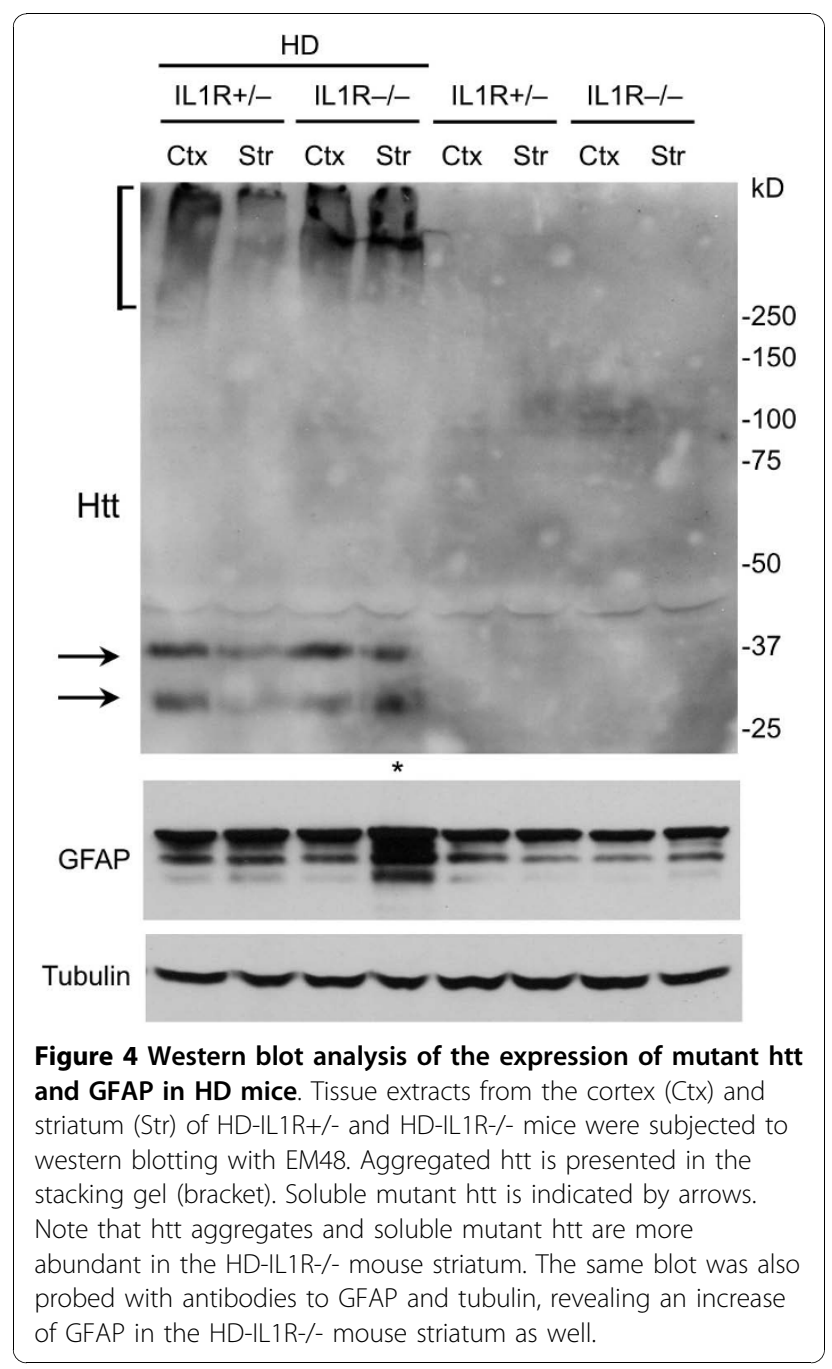

\section{Acknowledgements}

This work is supported by grants from the National Institutes of Health (AG019206 and NS041669 to XJL; NS045016 and AG031153 to SHL).

\section{Authors' contributions}

The experimental work was designed and performed by CEW. SHL was involved in experiment design and manuscript writing. XJL was involved in experiment design and manuscript writing. All authors read and approved the final manuscript.

\section{Competing interests}

The authors declare that they have no competing interests.

Received: 1 October 2010 Accepted: 2 November 2010 Published: 2 November 2010

\section{References}

1. Gusella JF, MacDonald ME, Ambrose CM, Duyao MP: Molecular genetics of Huntington's disease. Arch Neurol 1993, 50:1157-1163.

2. Vonsattel JP, DiFiglia M: Huntington disease. J Neuropathol Exp Neurol 1998, 57:369-384.

3. Li XJ, Li SH: HAP1 and intracellular trafficking. Trends Pharmacol Sci 2005, 26:1-3.

4. Pineda JR, Pardo R, Zala D, Yu H, Humbert S, Saudou F: Genetic and pharmacological inhibition of calcineurin corrects the BDNF transport defect in Huntington's disease. Mol Brain 2009, 2:33.
5. Caviston JP, Holzbaur EL: Huntingtin as an essential integrator of intracellular vesicular trafficking. Trends Cell Biol 2009, 19:147-155.

6. Pardo R, Molina-Calavita M, Poizat G, Keryer G, Humbert S, Saudou F: pARIShtt: an optimised expression platform to study huntingtin reveals functional domains required for vesicular trafficking. Mol Brain 2010, 3:17.

7. Sadri-Vakili G, Cha JH: Mechanisms of disease: Histone modifications in Huntington's disease. Nat Clin Pract Neurol 2006, 2:330-338.

8. Havel LS, Li S, Li XJ: Nuclear accumulation of polyglutamine disease proteins and neuropathology. Mol Brain 2009, 2:21.

9. Schilling G, Becher MW, Sharp AH, Jinnah HA, Duan K, Kotzuk JA, Slunt HH, Ratovitski T, Cooper JK, Jenkins NA, Copeland NG, Price DL, Ross CA, Borchelt DR: Intranuclear inclusions and neuritic aggregates in transgenic mice expressing a mutant $\mathrm{N}$-terminal fragment of huntingtin. Hum $\mathrm{Mol}$ Genet 1999, 8:397-407.

10. Menalled LB, Chesselet MF: Mouse models of Huntington's disease. Trends Pharmacol Sci 2002, 23:32-39.

11. Heng MY, Detloff PJ, Albin RL: Rodent genetic models of Huntington disease. Neurobiol Dis 2008, 32:1-9.

12. Spulber S, Bartfai T, Schultzberg M: IL-1/LL-1ra balance in the brain revisited - evidence from transgenic mouse models. Brain Behav Immun 2009, 23:573-579.

13. Allan SM, Rothwell NJ: Cytokines and acute neurodegeneration. Nat Rev Neurosci 2001, 2:734-744

14. Glaccum MB, Stocking KL, Charrier K, Smith JL, Willis CR, Maliszewski C, Livingston DJ, Peschon JJ, Morrissey PJ: Phenotypic and functional characterization of mice that lack the type I receptor for IL-1. J Immunol 1997, 159:3364-3371.

15. Mattson MP: NF-kappaB in the survival and plasticity of neurons. Neurochem Res 2005, 30:883-893.

16. Pizzi M, Spano P: Distinct roles of diverse nuclear factor-kappaB complexes in neuropathological mechanisms. Eur J Pharmacol 2006, 545:22-28.

17. Reijonen S, Kukkonen JP, Hyrskyluoto A, Kivinen J, Kairisalo M, Takei N, Lindholm D, Korhonen L: Downregulation of NF-kappaB signaling by mutant huntingtin proteins induces oxidative stress and cell death. Cell Mol Life Sci 2010, 67:1929-1941.

18. Khoshnan A, Ko J, Watkin EE, Paige LA, Reinhart PH, Patterson PH: Activation of the lkappaB kinase complex and nuclear factor-kappaB contributes to mutant huntingtin neurotoxicity. J Neurosci 2004, 24:7999-8008.

19. Patel HC, Boutin H, Allan SM: Interleukin-1 in the brain: mechanisms of action in acute neurodegeneration. Ann N Y Acad Sci 2003, 992:39-47.

20. Arend WP: Interleukin-1 receptor antagonist. Adv Immunol 1993, 54:167-227.

21. Wang CE, Tydlacka S, Orr AL, Yang SH, Graham RK, Hayden MR, Li S, Chan AW, Li XJ: Accumulation of N-terminal mutant huntingtin in mouse and monkey models implicated as a pathogenic mechanism in Huntington's disease. Hum Mol Genet 2008, 17:2738-2751.

22. Shin JY, Fang ZH, Yu ZX, Wang CE, Li SH, Li XJ: Expression of mutant huntingtin in glial cells contributes to neuronal excitotoxicity. I Cell Biol 2005, 171:1001-1012.

23. Yu ZX, Li SH, Evans J, Pillarisetti A, Li H, Li XJ: Mutant huntingtin causes context-dependent neurodegeneration in mice with Huntington's disease. J Neurosci 2003, 23:2193-2202.

24. Lin CH, Tallaksen-Greene S, Chien WM, Cearley JA, Jackson WS, Crouse AB, Ren S, Li XJ, Albin RL, Detloff PJ: Neurological abnormalities in a knock-in mouse model of Huntington's disease. Hum Mol Genet 2001, 10:137-144.

25. Wellington $C L$, Leavitt $B R$, Hayden MR: Huntington disease: new insights on the role of huntingtin cleavage. J Neural Transm Suppl 2000, 1-17.

26. Vassar R: beta-Secretase, APP and Abeta in Alzheimer's disease. Subcell Biochem 2005, 38:79-103.

27. Kanthasamy AG, Kitazawa M, Yang Y, Anantharam V, Kanthasamy A: Environmental neurotoxin dieldrin induces apoptosis via caspase-3dependent proteolytic activation of protein kinase C delta (PKCdelta): Implications for neurodegeneration in Parkinson's disease. Mol Brain 2008, 1:12.

28. Qiao $L$, et al: Lysosomal enzyme cathepsin D protects against alphasynuclein aggregation and toxicity. Mol Brain 2008, 1:17.

29. Cullen V, Lindfors $M, N g$ J, Paetau A, Swinton E, Kolodziej P, Boston $H$, Saftig P, Woulfe J, Feany MB, Myllykangas L, Schlossmacher MG, Tyynela J: 
Cathepsin D expression level affects alpha-synuclein processing, aggregation, and toxicity in vivo. Mol Brain 2009, 2:5.

30. O'Connor JJ, Coogan AN: Actions of the pro-inflammatory cytokine IL-1 beta on central synaptic transmission. Exp Physiol 1999, 84:601-614.

31. Viviani B, Gardoni F, Marinovich M: Cytokines and neuronal ion channels in health and disease. Int Rev Neurobiol 2007, 82:247-263.

32. Schafers M, Sorkin L: Effect of cytokines on neuronal excitability. Neurosci Lett 2008, 437:188-193.

33. Spulber S, Oprica M, Bartfai T, Winblad B, Schultzberg M: Blunted neurogenesis and gliosis due to transgenic overexpression of human soluble IL-1ra in the mouse. Eur J Neurosci 2008, 27:549-558.

34. Ohtsuki T, Ruetzler CA, Tasaki K, Hallenbeck JM: Interleukin-1 mediates induction of tolerance to global ischemia in gerbil hippocampal CA1 neurons. J Cereb Blood Flow Metab 1996, 16:1137-1142.

35. Ravizza T, Vezzani A: Status epilepticus induces time-dependent neuronal and astrocytic expression of interleukin-1 receptor type I in the rat limbic system. Neuroscience 2006, 137:301-308.

36. Bradford J, Shin JY, Roberts M, Wang CE, Li XJ, Li S: Expression of mutant huntingtin in mouse brain astrocytes causes age-dependent neurological symptoms. Proc Natl Acad Sci USA 2009, 106:22480-22485.

37. Gu XL, Long CX, Sun L, Xie C, Lin X, Cai H: Astrocytic expression of Parkinson's disease-related A53T alpha-synuclein causes neurodegeneration in mice. Mol Brain 2010, 3:12.

doi:10.1186/1756-6606-3-33

Cite this article as: Wang et al:: Lack of interleukin-1 type 1 receptor enhances the accumulation of mutant huntingtin in the striatum and exacerbates the neurological phenotypes of Huntington's disease mice. Molecular Brain 2010 3:33.

\section{Submit your next manuscript to BioMed Central and take full advantage of:}

- Convenient online submission

- Thorough peer review

- No space constraints or color figure charges

- Immediate publication on acceptance

- Inclusion in PubMed, CAS, Scopus and Google Scholar

- Research which is freely available for redistribution

Submit your manuscript at www.biomedcentral.com/submit
C Biomed Central 